$\checkmark$ Research Square

\title{
Biosynthesis of silver nanoparticles from Pseudomonas fluorescens and their antifungal activity against Aspergillus niger and Fusarium udum
}

\section{Aneesh Sikka}

Professor Jayashankar Telangana State Agricultural University

Triveni Sodimalla

Professor Jayashankar Telangana State Agricultural University

YALAVARTHI NAGARAJU ( $\nabla$ nagarajulvrth62@gmail.com )

Acharya N.G.Ranga Agricultural University https://orcid.org/0000-0003-2326-9427

\section{Research Article}

Keywords: Silver nanoparticles, Pseudomonas sp., Fusarium udum, Aspergillus niger, DLS, TEM etc.,

Posted Date: October 4th, 2021

DOI: https://doi.org/10.21203/rs.3.rs-942499/v1

License: (c) (i) This work is licensed under a Creative Commons Attribution 4.0 International License.

Read Full License 


\section{Abstract}

In recent years, emerging plant diseases have posed a significant danger to global economies. Fungicide resistance and climate change are the two primary sources of pathogen outbreaks. The silver nanoparticles have been demonstrated to restrain pathogenic bacteria, fungi, and viruses with minimal risk of developing resistance and phytotoxicity. The synthesis of silver nanoparticles via chemical and physical methods raises concerns about environmental safety and production costs. The microbial biofabrication of silver nanoparticles is simple, cost-effective, and ready-to-use technology. In the current investigation, we used Pseudomonas fluorescens cell filtrates for the synthesis of silver nanoparticles. The silver nanoparticles were characterized using Dynamic Light Scattering (DLS), zeta potential (Z), UVVis spectroscopy, SPR analysis, Transmission Electron Microscopy. Both silver nanoparticles and $\mathrm{AgNO}_{3}$ were tested for their ability to inhibit two phytopathogenic fungi, i.e., Fusarium udum and Aspergillus niger. Potent inhibition of mycelial growth was observed when silver nanoparticles were used at a concentration of $150 \mathrm{ppm}$. However, further research is needed to assess the toxicity of AgNPs before they are mass-produced and used in agricultural applications.

\section{Introduction}

Nanotechnology was introduced by Physicist and Nobel laureate Professor Richard Feynman in 1959. The synthesis and application of nanomaterials in different investigation fields are called Nanotechnology (Duran et al., 2005). Nanoparticles act as fundamental building blocks for nanotechnology. Drexler (1986) was the first to report atoms or molecules self-assembling at the nanoscale; since then, rapid and expansive research has occurred worldwide. Designing, synthesizing, and working with molecular systems below $100 \mathrm{~nm}$ is popularly communicated as nanotechnology. Nanotechnology is a rapidly growing field with interdisciplinary applications, especially in biology. Because of multiple applications, demand is increasing at an overwhelming rate concurrently manifested production is also recorded. Nanoparticles are synthesized from silver, gold, platinum, and palladium (noble metals); among these, silver nanoparticles (AgNPs) are most explored (Roy and Barik, 2010). Nanomaterials are synthesized using either chemical or physical methods, including sol process, micelle, chemical precipitation, hydrothermal method, pyrolysis, and chemical vapor deposition. Often, these chemical and physical methods of preparing nanoparticles require high-end toxic chemicals and consume vast quantities of energy reflected in their cost and restrict their avenues of applications, biology in particular, due to toxicity.

The future of nanotechnology relies on developing efficient and eco-friendly nanomaterial synthesis protocols among a variety of biological compositions, proportions, shapes, and elevated monodispersity. Biosynthesis of nanoparticles is an attractive opportunity to advance green nanotechnology, which can attain multiple applications, particularly in biology and agriculture. Bansal et al. (2011) stated that nanoparticles' biosynthesis is a bottom-up method that combines the mechanism of reduction or oxidation. Several microorganisms have been utilized to synthesize AgNPs through either intracellular or extracellular (Klaus et al., 1999; Nair and Pradeep, 2002; Mukherjee et al., 2001; and Ahmad et al., 2003) 
mechanisms. For instance, Ag containing nanocrystals of different compositions were synthesized by Pseudomonas stutzeri AG259 bacterium (Klaus et al., 1999). In Fusarium oxysporum fungus, the reduction of $\mathrm{Ag}^{+}$ions was attributed to an enzymatic process involving $\mathrm{NADH}$ - dependent reductase (Ahmad et al., 2003). Pseudomonas fluorescens produces extracellular reductases and metabolites, which are essential for producing AgNPs (Tang et al., 2017). Different microorganisms employ different mechanisms to produce nanoparticles; however, most of them make nanoparticles by reducing the metal ions (Li et al., 2011).

Silver has been recognized for its antimicrobial activity since the nineteenth century; nevertheless, the use of silver nanoparticles in the treatment of phytopathogenic fungi is gaining traction nowadays. Silver nanoparticles are known for their intense antifungal activity against Alternaria alternata (Ouda, 2014), Botrytis cinera (Ouda, 2014), Gloeophyllum abietinum (Narayanan and Park, 2014), G. trabeum, Chaetomium globosum, Phanerochaete sordida (Narayanan and Park, 2014), Trichophyton rubrum (Pereria et al., 2014), Setosphaeria turcica (Huang et al., 2020), Fusarium oxysporum (Gopinath and Velusamy, 2013), and yeast Malassezia furfur (Mussin et al., 2019). However, only a few studies have reported the antifungal effects of AgNPs on Fusarium udum and Aspergillus niger.

Diseases like collar rot (Aspergillus niger) and wilt (Fusarium udum) decrease yields by 50 per cent (Ghewande et al., 2002) and 30-100 per cent (Dhar et al., 2005), respectively, in groundnut and pigeon pea. The disease incidence of Fusarium and Aspergillus has been increasing year after year, and most of the released cultivars became susceptible to these diseases due to increased virulence in the pathogen (Sharma et al., 2016). However, the efficacy of commercialized existed fungicides is low as most organisms are resistant. Seed dressing with fungicides was found promising (Gangopadhyay et al., 1996); however, the development of resistance is a big concern nowadays, and besides that, damage of soil microflora needs to be addressed for environmental stability. Therefore, there is a need to develop new fungicide formulations with enhanced efficiency against various disease-causing pathogens in agriculture using emerging technologies like nanotechnology.

The small silver nanoparticles, which invariably have a high surface-to-volume ratio, improve antimicrobial activity by interacting with a diverse spectrum of receptors (Reidy et al., 2013). While silver has well-known toxic effects on microorganisms, the processes by which it exerts its bioactivity are not well understood or accepted (Reidy et al., 2013). Silver inhibits a broad range of microorganisms by altering cell membrane composition and function (Mc Donnell et al., 1999) and interferes with ATP production by altering associated proteins' expression (Yamanaka et al., 2005). Silver interferes with the DNA replication, forms reactive oxygen species (ROS), and deactivates the proteins by interacting with the thiol group (Davies and Etris, 1997).

In the present investigation, we aim to gain a better insight into the characteristics of the AgNPs using Dynamic Light Scattering (DLS), Ultraviolet-Visible spectroscopy (UV-Vis), zeta potential, and Transmission Electron Microscopy (TEM). We also evaluated the antifungal efficacy by applying different concentrations of AgNPs against the Fusarium udum and Aspergillus niger. 


\section{Material And Methods}

\section{Isolation and identification of pathogens}

A total of twenty plant samples of groundnut and pigeon pea were collected. The collected samples were utilized for the isolation of pathogens by the tissue segment method. In brief, the infected portions were cut into $1 \mathrm{~cm}$ bits with sterile surgical blades, and the surfaces were sterilized by dipping in 0.1 per cent (\%) sodium hypochlorite $(\mathrm{NaOCl})$ for 30 seconds followed by three times washing in sterile distilled water. These cuttings were placed on the sterilized Potato Dextrose Agar (PDA) plates and incubated at $28 \pm 2$ ${ }^{0} \mathrm{C}$ in the BOD incubator for 5-7 days (Rangaswamy et al., 1999). The isolates were purified using the hyphal tip technique and maintained on PDA slants at $4{ }^{\circ} \mathrm{C}$ until further use. The DNA was isolated from the fungal culture, and its quality was evaluated on $1.0 \%$ agarose gel. The DNA of large subunit and Internal Transcribed Spacer (ITS) region was amplified using ITS1 (5'-TCC GTA GGT GAA CCT GCG G-3') and ITS 4 (5'-TCC TCC GCT TAT TGA TAT GC-3') as described by White et al. (1990). A single discrete PCR amplicon band of $~ 800$ bp was observed when resolved on an agarose gel. This region sequence was used to carry out BLAST with NCBI Genbank's database, and the same was submitted for obtaining accession numbers. The pure culture of Pseudomonas fluorescens strain PS898 (isolated from the rhizosphere of chilli) was obtained from the Department of Agricultural Microbiology and Bioenergy, Hyderabad, India.

\section{Bio-fabrication of silver nanoparticles from Pseudomonas fluorescens}

A three-day-old Pseudomonas fluorescens pure culture was inoculated into $100 \mathrm{ml}$ of King's B Broth and incubated at $28 \pm 2{ }^{\circ} \mathrm{C}$ in an orbital shaker $(120 \mathrm{rpm})$. The biomass was harvested after 3 Days of inoculation through sterilized Whatman No.1 filter paper. After biomass harvesting, approximately $2 \mathrm{ml}$ of culture filtrate of Pseudomonas fluorescens was treated with the $50 \mathrm{ml}$ of $1 \mathrm{mM} \mathrm{AgNO}_{3}$ aqueous solution (odorless, boiling point $440{ }^{\circ} \mathrm{C}$, molar mass $169.87 \mathrm{~g} / \mathrm{mol}$, density $4.35 \mathrm{~g} / \mathrm{cm}^{3}$ ) for the synthesis of silver nanoparticles. The whole mixture was incubated at room temperature for $72 \mathrm{~h}$; change in media color from colorless to brown color confirms the formation of silver nanoparticles through reduction of silver ionic forms $\mathrm{Ag}^{+}$to $\mathrm{Ag}^{0}$ (Adrian et al., 2020).

\section{Ultraviolet-Visible (UV-Vis) spectroscopy analysis of nanoparticles}

The reduction of silver $\left(\mathrm{Ag}^{+}\right)$ions in the reaction mixture were monitored using a UV-Vis spectrophotometer $24 \mathrm{~h}$. The Localised Surface Plasmon Resonance (LSPR) of AgNPs in the reaction mixture was recorded using UV-Visible spectrophotometer (Shimadzu, UV2450) between the wavelengths 200 to 800 nm (Shreya et al., 2015, Ojo et al., 2017, Kumar et al., 2017).

\section{Transmission Electron Microscopy (TEM)}

Dispersion, shape, and size of bio-fabricated silver nanoparticles were analyzed by using Transmission Electron Microscopy (JEOL (JEM-1010)), with an accelerating voltage of $80 \mathrm{kV}$ (Adrian et al., 2020). A 
drop of aqueous AgNPs was dried on the carbon-coated copper TEM grids and kept under vacuum in desiccators before loading them onto a specimen holder. The particle size distribution of silver nanoparticles was evaluated using ImageJ 1.45 software.

\section{Dynamic Light Scattering (DLS) and Zeta potential analysis}

The aqueous suspension of silver nanoparticles was filtered through a $0.22 \mu \mathrm{m}$ syringe-driven filter unit. The filtrate was used to evaluate the size based on the Dynamic Light Scattering technique principle made in a Nanoparticle SZ-100 series compact scattering spectrometer (Mahmoodreza et al., 2019). The surface zeta potentials of nanoparticles were measured using a Laser zeta meter (Malvern zeta seizer 2000, Malvern). In brief, $5 \mathrm{ml}$ of liquid samples (nanoparticles) were diluted with $50 \mathrm{ml}$ of DDW (double distilled water) using $\mathrm{NaCl}$ as suspending electrolyte solution $\left(2 \times 10^{-2} \mathrm{M} \mathrm{NaCl}\right)$, and the samples were shaken for 30 minutes. After shaking, zeta potential and $\mathrm{pH}$ were recorded, and the metallic particles were measured. Zeta potential values were used to determine the surface potential of the silver nanoparticles. In each case, an average of three separate measurements was reported, and the stability of NP's was measured when the zeta potential values ranged from higher than $+30 \mathrm{mV}$ to lower than $-30 \mathrm{mV}$ (Akman et al., 2011).

\section{Assessment of silver nanoparticles biocontrol potential against Aspergillus niger and Fusarium udum}

The silver nanoparticles (approximately $0.0002 \mathrm{mg}$ ) were mixed at the rate of 5, 15, 25, 50, and $75 \mu \mathrm{l}$ in $1000 \mathrm{ml}$ of modified PDA medium (Potatoes-400 g, Dextrose-40 g, Agar-40 g, distilled water-1000 ml) to obtain a final concentration of $10,30,50,100$, and $150 \mathrm{ppm}$ respectively. Similarly, required concentrations of $\mathrm{AgNO}_{3}$ were achieved by mixing 10,30,50,100, and $150 \mathrm{mg} / \mathrm{l}$ of media. The control was maintained without AgNPs and $\mathrm{AgNO}_{3}$, respectively. Mycelial discs $(7 \mathrm{~mm})$ of $24 \mathrm{~h}$-old pathogens were inoculated at the center of the plates and incubated at $28 \pm 2{ }^{\circ} \mathrm{C}$ until total growth was observed in control treatment. The bacterial filtrate of $P$. fluorescence $(20 \mu \mathrm{l})$ was spread on the $6 \mathrm{~mm}$ filter discs and placed in one end of the PDA plates, and the other end was inoculated with mycelial discs. In each treatment, five replications were maintained. The per cent inhibition of radial growth of the test pathogens Aspergillus niger and Fusarium udum were calculated using the following formula.

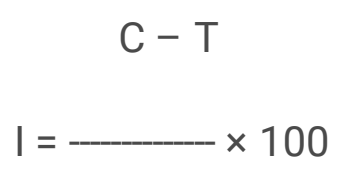

C

Where,

$\mathrm{I}=$ Percent reduction in the growth of $A$. niger and $F$. udum 
$\mathrm{C}=$ Radial growth $(\mathrm{mm})$ in control

$\mathrm{T}=$ Radial growth $(\mathrm{mm})$ in treatments

\section{Results And Discussion}

\section{Isolation and identification of pathogens}

Aspergillus niger (collar rot) affected seeds with blackish testa and rotted internal tissue, and also mature plants with wilting and rotting symptoms were collected at just below the ground level. The affected portion turned dark, shrunken, and shredded, and later covered by black spores of the pathogen. The pathogen was identified as Aspergillus niger based on microscopic examination (Figure 1). The fungus displayed upright and tiny conidiophores, finishing with globose swelling, holding phialides radiating from the entire surface. The conidia were single-celled, light to dark brown, globose shaped, and produced basipetal (Figure 1a and b). Mycelium was hyaline branched and septate.

The wilt (Fusarium udum) pathogen isolated from the infected plant roots of pigeon pea had slender hyaline hyphae with abundant branching, typically with small aerial growth (Figure 2). Chlamydospores were globose and smooth-walled. Macroconidia were straight to falcate, thin-walled, septate but predominantly 3-septate. Microconidia fusiform to reniform, septate (Figure 2a and b), micro and macroconidia formation were observed under the compound microscope. The isolates' nucleotide sequence has $100 \%$ identity with Aspergillus niger isolate PP2 and Fusarium udum isolate PP1. The sequences were submitted to NCBI-GenBank with the accession numbers MW826097 (A. niger) and MW826105 (F. udum).

\section{Biofabrication of silver nanoparticles and characterization}

The majority of metal nanoparticles have optical properties that are proportional to the size and form. The bio-fabrication of silver nanoparticles (AgNPs) has been verified using a notable transition in media color from yellow to brown after 24 hours of incubation (Figure 3), signaling the biotransformation of $\mathrm{Ag}^{+}$ to $\mathrm{Ag}^{0}$ by reductive enzymes (Ahmad et al., 2003; Saifuddin et al., 2009). The variation in the organism physiology and the size and shape of metal particles could explain the current sample's over-color development. The variation in relative behavior in reducing silver nitrate ions to metal nanoparticles due to the proteins' existence may also explain the color shift. Surface plasmon vibration gives silver nanoparticles a peculiar brownish yellow color. Light evokes the free electrons in silver nanoparticles as observed under UV-Vis spectroscopy and transmits to a higher energy level, but the electron is unstable in an excited state and returns to base energy; a photon is emitted simultaneously (Thangaraju et al., 2012). Correspondingly, the spectrum of silver nanoparticles demonstrated the highest surface plasmon resonance at $420 \mathrm{~nm}$. Sharp Surface Resonance Plasmon (SRP) in the 350-600 nm range are commonly used to confirm the presence of silver nanoparticles in an aqueous solution (Sastry et al., 1998; Henglein, 1993). Figure 4 reveals that the SPR is in the $400-500 \mathrm{~nm}$ band, suggesting that bio-fabricated silver nanoparticles are smaller and identical in form. As per Mie's theory, only a single SPR band is expected in 
the absorption spectra of spherical nanoparticles whereas, the number of peaks increases as anisotropy increases (Raut Rajesh et al., 2009). We also recorded a single peak in the present study that indicates the silver nanoparticles are spherical. This finding was the primary confirmation of size, form, and distribution, further verified by TEM analysis.

TEM micrographs demonstrated the size and form of individual bio-fabricated silver nanoparticles (Figure 5). With an average size of $30 \mathrm{~nm}$ with slight agglomeration, they are quasi-spherical to spherical in form and anisotropic in nature. These observations follow the findings of the small-sized nanoparticles of distinct shapes found by Abdel-Raouf et al. (2018). When the zeta potential is greater than $30 \mathrm{mV}$, the particles are stable (Sapsfor et al., 2011), consistent with the high zeta potential observed $(-42.7 \mathrm{mV})$.

The particle size distribution of bio-fabricated silver nanoparticles has been evaluated with Dynamic Light Scattering (DLS). According to the findings, the mean size of bio-fabricated silver nanoparticles was estimated to be approximately $66.0 \mathrm{~nm}$ (Figure 6), with the graph peak tend to range from 32 to $115 \mathrm{~nm}$, indicating that variable sizes of AgNPs were found in the solution. The TEM images of 50, 100, and 150 ppm concentrations of silver nanoparticles revealed the sizes as $49.7,41.3$, and $78.5 \mathrm{~nm}$, respectively. This evidence is in good agreement with the DLS measurements. As predicted, due to the variations in measurements by the devices, the DLS calculated value is marginally larger than the TEM calculated value i.e., TEM calculates the number based on the size distribution of the physical dimension without capping agent. At the same time, the DLS measures the hydrodynamic diameter, that is, the particle diameter as well as the ions or molecules that are connected and travel along with them in silver nanoparticles in solution (Huang et al., 2007).

Additional insight into the stability of the bio-fabricated silver nanoparticles was checked using zeta potential. The zeta potential's magnitude determines the colloid's potential stability; particles with more positive than $+30 \mathrm{mV}$ or more negative than $-30 \mathrm{mV}$ were presumed stable (Melendrez et al., 2010; and Vimala et al., 2017). We have observed the zeta potential peak at $-70 \mathrm{mV}$, demonstrating the robust stability of silver nanoparticles at $\mathrm{pH}=7 \pm 0.2$ (Figure 7). High negative zeta potential might have occurred due to the interaction of silver nanoparticles with protein, peptides, or lipids of bacteria, which increases the negative zeta potential of silver nanoparticles (Shannahan et al., 2013). Our zeta potential results suggest that silver nanoparticles were highly stable and aggregated; similar results were reported by Loza et al. (2014). It thus confirms the presence of highly stable and aggregating AgNPs.

\section{Antifungal potentials of silver nanoparticles}

Due to expanded tolerance to fungicides and antibiotics, silver nanoparticles have recently sparked interest in the field of phytopathogenic fungi regulation. The bio-fabricated silver in the current research has demonstrated excellent in vitro inhibition of phytopathogenic fungi. However, because the current research is focused on in vitro petri dish testing, the extrapolation of the results to more general cases is minimal. Nonetheless, these findings include valid preliminary efficacy evidence on silver compounds used in plant-pathogen control. In the present investigation, silver nanoparticles inhibited the growth of Aspergillus niger and Fusarium udum significantly. The inhibition of mycelia formation by AgNPs and 
$\mathrm{AgNO}_{3}$ at various concentrations was assessed regularly for all of the fungi tested and the negative control. Bacterial filtrate of Pseudomonas fluorescens has no discernible impact on the mycelial growth of two phytopathogens ( $p>0.05$ ). The bacterial filtrate treatment inhibited $A$. niger up to 7.7 per cent and $F$. udum up to 4.2 per cent.

The quantified results revealed that the antifungal activities of the AgNPs varied depending on the fungi studied and the concentrations used. In comparison to the control, AgNPs substantially inhibited the mycelial development of Aspergillus niger and Fusarium udum in a concentration-dependent manner $(p<0.05)$. Fusarium udum had the best mycelial inhibition of 100 per cent among the studied fungi. The least successful concentration of bio-fabricated silver nanoparticles against Fusarium udum was 10 ppm, which inhibited mycelial development by 55.5 per cent. According to the statistical analysis, antifungal effect of $\mathrm{AgNO}_{3}$ was significantly lower than AgNPs on Fusarium udum ( $\left.p>0.05\right)$. Rabab et al. (2018), reported that silver nanoparticles inhibited Fusarium sp. by 68.2 per cent at 150 ppm concentration. We observed 100 per cent antifungal activity against Fusarium udum at the same concentration (150 ppm). In several studies, AgNPs have demonstrated a broad spectrum of action against Fusarium sp., Cadndia tropicalis (Rahisuddin et al., 2015), Trichophyton rubrum (Pereira et al., 2014), Rhizoctonia solani, Colletotrichum sp. (Balakumaran et al., 2015). However, the methods used for biosynthesis and particle size differed depending on the experiment. We should note that the antifungal activity of silver nanoparticles varies depending on the type of fungus and the size of silver nanoparticles (Shafaghat, 2015).

The effect of silver nanoparticles on the mycelial growth of $A$. niger was slightly lower than the $\mathrm{AgNO}_{3}$. We observed that geometric mean and mode were higher for $\mathrm{AgNO}_{3}$ as compared to AgNPs. The per cent inhibition of Aspergillus niger and Fusarium udum was 87.19 and 74.8 per cent, respectively, at 150 ppm of $\mathrm{AgNO}_{3}$ concentration (Figures 8 and 9). Our results are in agreement with the findings of El-Kadi et al. (2018), who reported that $\mathrm{AgNO}_{3}$ inhibited Aspergillus sp. efficiently than other fungi. Furthermore, none of the isolates exhibited tolerance to silver nanoparticles. However, correlation with other studies is required to confirm the mode of action of AgNPs. It was believed that the antimicrobial activity of silver nanoparticles was due to the binding of silver nanoparticles on the mycelium leads to the formation of pores (Young et al., 2009) and electrolytes leakage from cells. The destabilization of cell membrane integrity (Kim et al., 2009a) and related proteins and lipids leads to respiratory inhibition and, eventually, cell lysis (Durán et al., 2005). Interaction of AgNPs with phosphorous and sulfhydryl groups in the cells leads to DNA damage, transcriptional interference (Feng et al., 2000; and Yamanaka et al., 2005), and protein inactivation (Durán et al., 2005).

\section{Conclusions}

The extensive use of fungicides resulted in fungicide resistance and ecological destruction. AgNPs are a novel antimicrobial agent with several benefits, including multiple modes of action and a lower likelihood of triggering resistance. The immediate need for information, evaluation, and characterization of these 
materials poses several scientific and technological challenges. In this study, spherical-shaped silver nanoparticles were biosynthesized from $P$. fluorescence. The biosynthesis of AgNPs was confirmed using a UV-Vis spectrophotometer, which showed an absorption peak at $420 \mathrm{~nm}$. TEM micrographs and DLS analysis confirmed the shape and size of AgNPs. The particle size ranged from 30 to $80 \mathrm{~nm}$ with moderate to low aggregation. Silver nanoparticles had strong antifungal activity in vitro against Fusarium udum and Aspergillus niger, with the inhibition zone's diameter differing depending on the fungal species and concentration of AgNPs used.

From this study, we can conclude AgNPs can be used as biopesticides. However, major concerns, such as physiological, safety, phytotoxicity, etc., should be resolved before commercial production and application. More research is required to understand the exact molecular mechanism that leads to the development of AgNPs by biological methods so that the size and polydispersity of these nanoparticles can be better regulated. Simultaneously, environmental monitoring of silver in the field is critical for evaluating its impact on the environment and human health. Furthermore, this study did not address the biocontrol mechanisms; however, there is plenty of space for future studies to use AgNPs in agriculture to control plant pathogens.

\section{Statistical analysis}

Experiments were conducted in Completely Randomised Design (CRD). Data were analyzed following the statistical methods outlined by Gomez and Gomez (1984).

\section{Declarations}

\section{Ethics approval and consent to participate}

Not applicable

\section{Consent for publication}

Not applicable

\section{Availability of data and material}

Not applicable

\section{Competing interests}

Authors declare that they have no competing interests with any organization or persons

\section{Funding}

Not applicable 


\section{Authors' contributions}

Dr. S. Triveni formulated the study, Mr. S. Aneesh and Dr. Nagaraju Executed the work and written the paper under the guidance of Dr.S Triveni

\section{References}

1. Abdel-Raouf N, Al-Enazi NM, Ibraheem IBM, Alharbi RM, Alkhulaif MM (2018) Biosynthesis of silver nanoparticles by using of the marine brown alga Padina pavonia and their characterization. Saudi $\mathrm{J}$ Biol Sci

2. Adrian M, Sorin M, Gabi MM, Gina C, Calina PC (2020) Biosynthesis of silver nanoparticles mediated by culture filtrate of lactic acid bacteria, characterization and antifungal activity. Eurobitoech $\mathrm{J}$ 4(2):97-103

3. Ahmad A, Mukherjee P, Senapati S (2003) Extracellular biosynthesis of silver nanoparticles using the fungus Fusarium oxysporum. Colloids Surf 28(4):313-318

4. Akman E, Genc Oztoprak B, Gunes M, Kacar E, Demir A (2011) Effect of femtosecond Ti:Sapphire laser wavelengths on plasmonic behaviour and size evolution of silver nanoparticles, photon nanostruct. Fundam Appl 9:276-286

5. Amr TM, Saeb, Ahmad S, Alshammari, Hessa AB, Khalid AAR (2014) Production of silver nanoparticles with strong and stable antimicrobial activity against highly pathogenic and multidrugresistant bacteria. The Scientific World J 9 http://dx.doi.org/10.1155/2014/704708

6. Balakumaran MD, Ramachandran R, Kalaichelvan PT (2015) Exploitation of endophytic fungus, Guignardia mangiferae for extracellular synthesis of silver nanoparticles and their in vitro biological activities. Microbiol Res 178:9-17. https://doi.org/10.1016/j.micres.2015.05.009

7. Bansal V, Ramanatham R, Bhargava SK (2011) Fungus mediated biological approaches towards green synthesis of oxide nanomaterials. Australian J Chemistry 64:279

8. Bragg PD, Rainnie DJ (1974) The effect of silver ions on the respiratory chains of Escherichia coli. Can J Microbiol 20:883-889

9. Davies RL, Etris SF (1997) The development and functions of silver in water purification and disease control. Catal Today 36:107-114

10. Dhar V, Reddy MV, Chaudhary RG (2005) Major diseases of pigeonpea and their management. In: Kumar AM eds S Advances in Pigeonpea Research. Indian Institute of Pulses Research;), Kanpur, pp 229-261

11. Drexler KE (1986) Engines of Creation-The Coming Era of Nanotechnology. Anchor Press/Doubleday, New York, pp 425-426

12. Durán N, Marcato PD, Alves OL, Souza G, Esposito E (2005) Mechanistic aspects of biosynthesis of silver nanoparticles by several Fusarium oxysporum strains. J Nanobiotechnol 3:1-8 
13. Duran N, Priscyla D, Marcato PD, Alves O, De Souza G, Esposito E (2005) Mechanistic aspects of biosynthesis of silver nanoparticles by several Fusarium oxysporum strains. J Nanobiotechnol 3:1-7

14. El-Kadi SK, Mohammed AEF, Khaled EH, Mostafa (2018) Comparison between silver nanoparticles and silver nitrate as antifungal agent. International Journal of Nanoscience Nanoengineering 4(1):511

15. Feng QL, Wu J, Chen GQ, Cui FZ, Kim TN, Kim JO (2000) A mechanistic study of the antibacterial effect of silver ions on Escherichia coli and Staphylococcus aureus. J Biomed Mater Res 52:662668

16. Gangopadhyay S, Bhatia JV, Godara SI (1996) Evaluation of fungicides for the control of collar rot of groundnut. Indian J Mycology Plant Pathology 26:278-279

17. Ghewande MP, Desai S, Basu MS (2002) Diagnosis and management of major diseases of groundnut. In Natinal Research Centre for Groundnut Buletien 8-9

18. Gomez KA, Gomez AA (1984) Statistical Procedures in Agricultural Research. Exp Agric 22:313-313

19. Gopinath V, Velusamy P (2013) Extracellular biosynthesis of silver nanoparticles using Bacillus sp. GP-23 and evaluation of their antifungal activity towards Fusarium oxysporum. Spectrochim Acta Part A Mol Biomol Spectrosc 106:170-174

20. Henglein A (1993) Physicochemical properties of small metal particles in solution: Microelectrode reactions, chemisorption, composite metal particles, and the atom-to-metal transition. J Physical Chemistry 97(21):5457-5471

21. Huang W, Yan M, Haiming D, Yaling B, Xinxin C, Haibing Y (2020) Synergistic antifungal activity of green synthesized silver nanoparticles and epoxiconazole against Setosphaeria turcica. Journal of Nanomaterials 1-7 https://doi.org/10.1155/2020/9535432

22. Huang J (2007) Nanotechnology 18:105

23. Kim SW, Kim KS, Lamsal K, Kim YJ, Kim (2009a) An in vitro study of the antifungal effect of silver nanoparticles on oak wilt pathogen Raffaelea sp. J Microbiol Biotechnol 19:760-764

24. Klaus T, Joerger R, Olsson E, Granqvist CG (1999) Silver-based crystalline nanoparticles, microbially fabricated. Proceedings of the National Academy of Sciences 96:1361

25. Kumar B, Smita K, Cumbal L, Debut A (2017) Green synthesis of silver nanoparticles using Andean blackberry fruit extract. Saudi J Biol Sci 24:45-50

26. Li X, Xu H, Chen ZS, Chen G (2011) Biosynthesis of nanoparticles by microorganisms and their applications. J Nanomater 1:1-16

27. Loza K, Diendorf J, Sengstock C, Ruiz-Gonzalez L, Gonzalez-Calbet JM, Vallet-Regi M, Koller M, Epple $M$ (2014) The dissolution and biological effects of silver nanoparticles in biological media. J Mater Chem B 2:1634-1643

28. Mahmoodreza B, Ayat HP, Ali N, Masood Z, Roya M, Aliyar M (2019) Facile green synthesis of silver nanoparticles using Berberis vulgaris leaf and root aqueous extract and its antibacterial activity. International J Biological Macromolecules 124:148-154 
29. McDonnell G, Russel AD (1999) Antiseptics and Disinfectants: Activity, action, and resistance. Clin Microbiol Rev 12:147

30. McDonnell G, Russell AD (1999) Antiseptics and disinfectants: activity, action, and resistance. Clin Microbiol Rev 12:147-179

31. Melendrez MF, ardenas GC, Arbiol J (2010) Synthesis and characterization of gallium colloidal nanoparticles. J Colloid Interface Science 346(2):279-287

32. Mukherjee P, Absar A, Deendayal M, Senapati S, Sudhakar RS, Mohammad, Renu P, Ajaykumar M, Alam R, Kumar, Murali S (2001) Fungus-mediated synthesis of silver nanoparticles and their immobilization in the mycelial matrix: A novel biological approach to nanoparticle synthesis. Nano lett 10:515-519

33. Mussin JE, Roldán MV, Rojas F (2019) Antifungal activity of silver nanoparticles in combination with ketoconazole against Malassezia furfur. AMB Expr 9:131. https://doi.org/10.1186/s13568-019-08577

34. Nair B, Pradeep (2002) Coalescence of nanoclusters and formation of submicron crystallites assisted by Lactobacillus Strains. Crystal Growth Design 2(4):293-298

35. Narayanan KB, Park HH (2014) Antifungal activity of silver nanoparticles synthesized using turnip leaf extract (Brassica rapa L.) against wood rotting pathogens. Eur J Plant Pathol 140:185-192. DOI 10.1007/s10658-014-0399-4

36. Ojo OA, Oyinloye BE, Ojo AB, Afolabi OB, Peters OA, Olaiya O, Fadaka A, Jonathan J, Osunlana O (2017) Green synthesis of silver nanoparticles (AgNPs) using Talinum triangulare (Jacq.) willd. leaf extract and monitoring their antimicrobial activity. J Bionanoscience 11:292-296

37. Ouda SM (2014) Antifungal activity of silver and copper nanoparticles on two plant pathogens, Alternaria alternata and Botrytis cinera. Res J Microb 9(1):34-42

38. Pereira L, Dias N, Carvalho J, Fernandes S, Santos C, Lima N (2014) Synthesis, characterization and antifungal activity of chemically and fungal-produced silver nanoparticles against Trichophyton rubrum. J Appl Microbiol 117:1601-1613. https://doi.org/10.1111/jam.12652

39. Rabab ME, Raida EAH, Awatif AH (2018) Biosynthesis and characterization of silver nanoparticles using Trichoderma longibrachiatum and their effect on phytopathogenic fungi. Egyptian Journal of Biological Pest Control 28:28. DOI:10.1186/s41938-018-0028-1

40. Rahisuddin Al-Thabaiti SA, Khan Z, Manzoor N (2015) Biosynthesis of silver nanoparticles and its antibacterial and antifungal activities towards Gram-positive, Gram-negative bacterial strains and diferent species of Candida fungus. Bioprocess Biosyst Eng 38:1773-1781. https://doi. org/10.1007/s00449-015-1418-3

41. Rangaswamy G, Mahadevan A (1999) Diseases of Crop Plants in India, 4th edn. Prentice Hall of India, Pvt. Ltd., New Delhi, p 607

42. Raut Rajesh W, Lakkakula JR, Kolekar NS, Mendhulkar VD, Kashid SB (2009) Phytosynthesis of silver nanoparticle using Gliricidia sepium (Jacq.). Current Nanoscience 5(1):117-122 
43. Reidy B, Haase A, Luch A, Dawson KA, Lynch I (2013) Mechanisms of silver nanoparticle release, transformation and toxicity: a critical review of current knowledge and recommendations for future studies and applications. Materials 6:2295-2350

44. Roy N, Barik A (2010) Green synthesis of silver nanoparticles from the unexploited weed resources. International J Nanotechnology 4:95

45. Saifuddin N, Wong CW, Yasumira AAN (2009) Rapid biosynthesis of silver nanoparticles using culture supernatant of bacteria with microwave irradiation. E-J Chem 6(1):61-70

46. Sapsford KE, Tyner KM, Dair JR, Deschamps IL, Medintz (2011) Analyzing nanomaterial bioconjugates: a review of current and emerging purification and characterization techniques. Anal Chem 83:4453-4488

47. Sastry M, Patil V, Sainkar SR (1998) Electrostatically controlled diffusion of carboxylic acid derivatized silver colloidal particles in thermally evaporated fatty amine films. J Physical Chemistry 102(8):1404-1410

48. Shafaghat A (2015) Synthesis and characterization of silver nanoparticles by phytosynthesis method and their biological activity. Synth React Inorg Metal-Org Nano-Metal Chem 45:381-387

49. Sharma M, Ghosh R, Telangre R, Rathore A, Saifulla M, Mahalinga DM, Saxena DR, Jain YK (2016) Environmental influences on Pigeonpea-Fusarium udum interactions and stability of genotypes to fusarium wilt. Front Plant Sci 7:253. DOI:10.3389/fpls.2016.00253

50. Shreya M, Amita H, Uttiya D, Paulomi B, Naba KM (2015) Biosynthesis of silver nanoparticles from Aloe vera leaf extract and antifungal activity against Rhizopus sp. and Aspergillus sp. Appl Nanosci $5: 875-880$

51. Tang L, Shi J, Wu H, Zhang S, Liu H, Zou H, Wu Y, Zhao J, Jiang Z (2017) In situ biosynthesis of ultrafine metal nanoparticles within a metal-organic framework for efficient heterogeneous catalysis. Nanotechnology 28:365604. DOI:10.1088/1361-6528/aa79e1

52. Thangaraju N, Venkatalakshmi R, Chinnasamy A, Kannaiyan P (2012) Synthesis of silver nanoparticles and the antibacterial and anticancer activities of the crude extract of Sargassum polycystum C, Agardh. Nano Biomed Eng 4:89-94

53. Vimala A, Sahaya S, Sathish, Thamizharasi T, Palani R, Vijayakanth P, Kavitha R (2017) Moss (Bryophyte) mediated synthesis and characterization of silver nanoparticles from Campylopus flexuosus (Hedw.). Bird J Pharm Sci Res 9(3):292-297

54. White TJ, Bruns T, Lee S, Taylor J (1990) Amplification and direct sequencing of fungal ribosomal RNA genes for phylogenetics. In: Innis MA et al (eds) PCR protocols: a guide to methods and applications. Academic Press, Inc., New York, pp 315-322

55. Yamanaka M, Hara K, Kudo J (2005) Bactericidal actions of a silver ion solution on Escherichia coli, studied by energy - filtering transmission electron microscopy and proteomic analysis. Appl Environ Microbi 71(11):7589-7593

56. Yamanaka M, Hara K, Kudo J (2005) Bactericidal actions of a silver ion solution on Escherichia coli, studied by energy-filtering transmission electron microscopy and proteomic analysis. Appl Environ 
Microbiol 71:7589-7593

57. Young KJ, Byung HK, Geunhwa J (2009) Antifungal activity of silver ions and nanoparticles on phytopathogenic fungi. Plant Dis 93:1037-1043

\section{Figures}
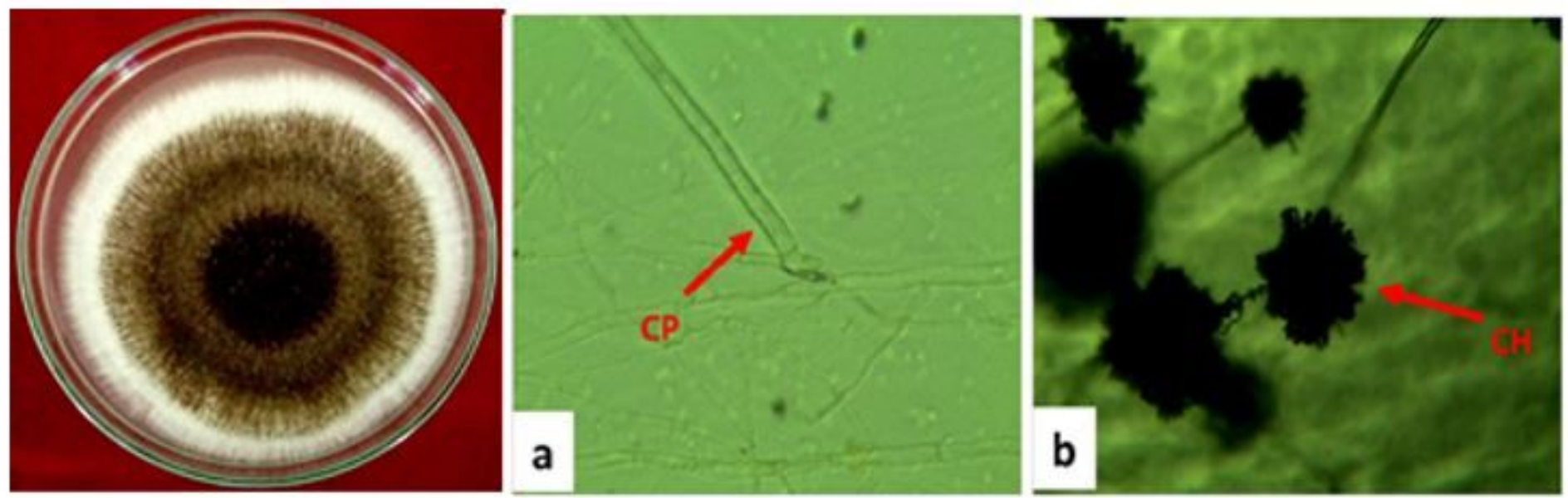

\section{Figure 1}

Growth of Aspergillus niger on potato dextrose agar and morphological characters of Aspergillus niger. a) Foot cell (FC) of conidiophore (CP) arising from hypha of Aspergillus niger b) Conidial head (CH)
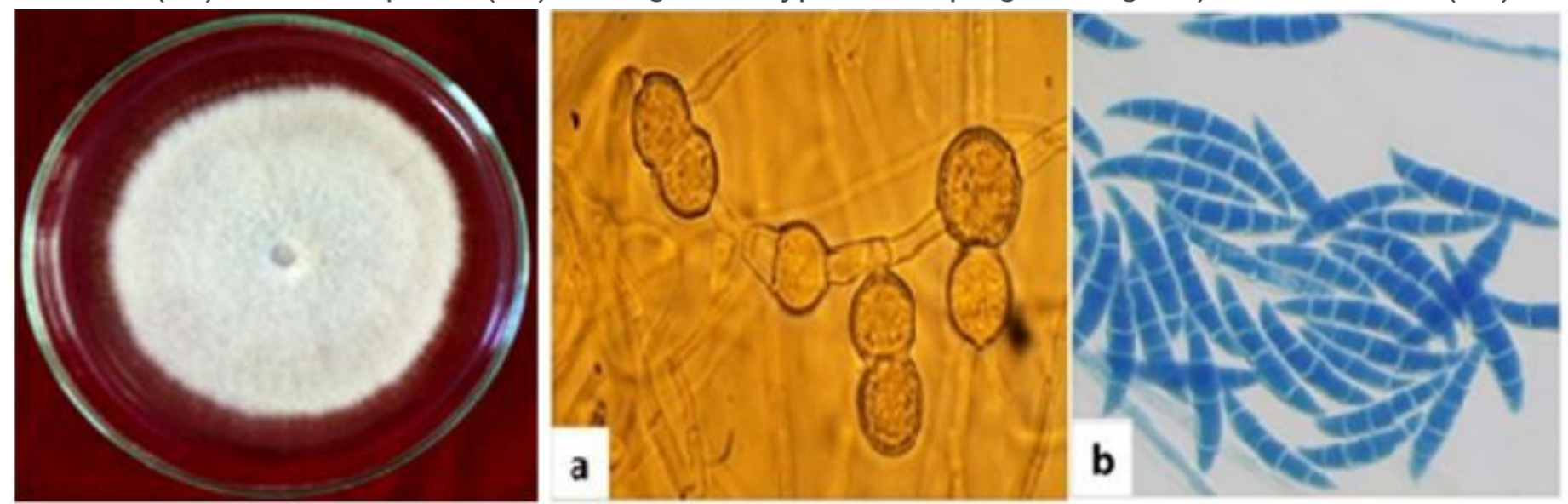

Figure 2

Growth of Fusarium udum isolate on potato dextrose agar and morphological characters of Fusarium udum a) Macroconidia b) Microconidia 


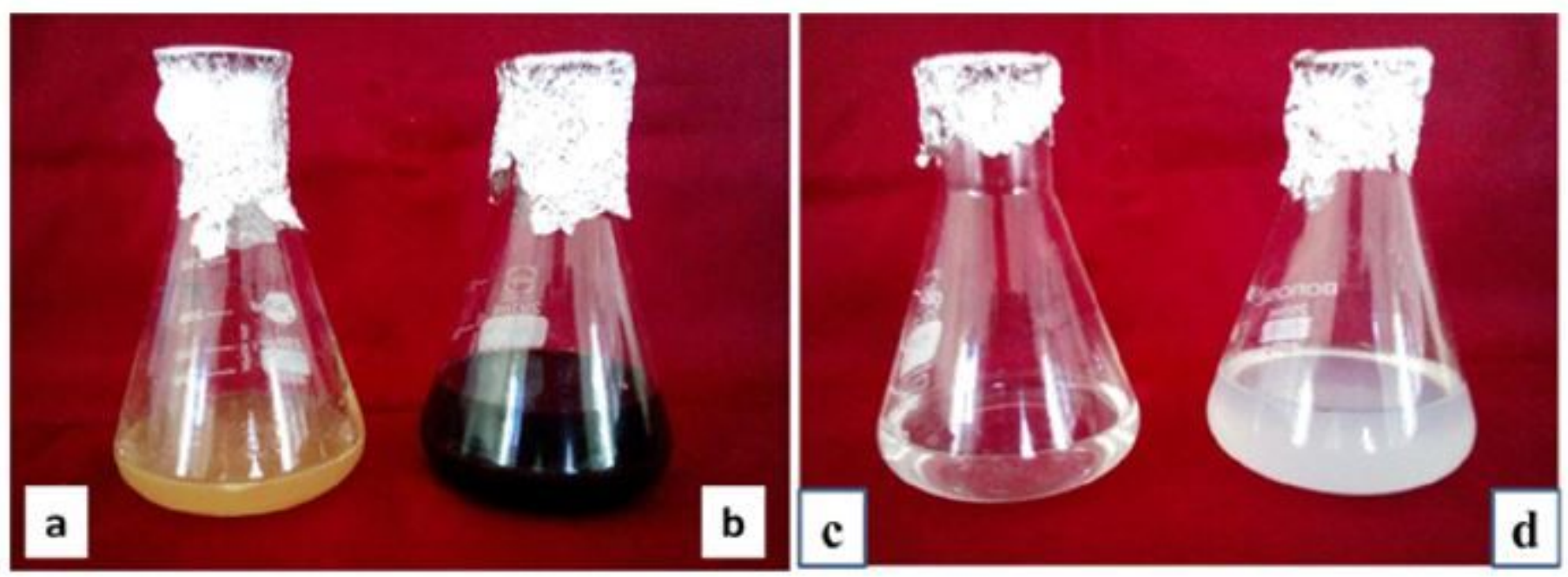

\section{Figure 3}

Synthesis of silver nanoparticles a) Culture filtrates of Pseudomonas spp at three days of incubation, b) Culture filtrate treated silver nitrate solutions after $24 \mathrm{~h}$ incubation, c) $1 \mathrm{mM} \mathrm{AgNO3}$ solution before $24 \mathrm{~h}$ incubation, d) $1 \mathrm{mM}$ AgNO3 solution after $24 \mathrm{~h}$ incubation

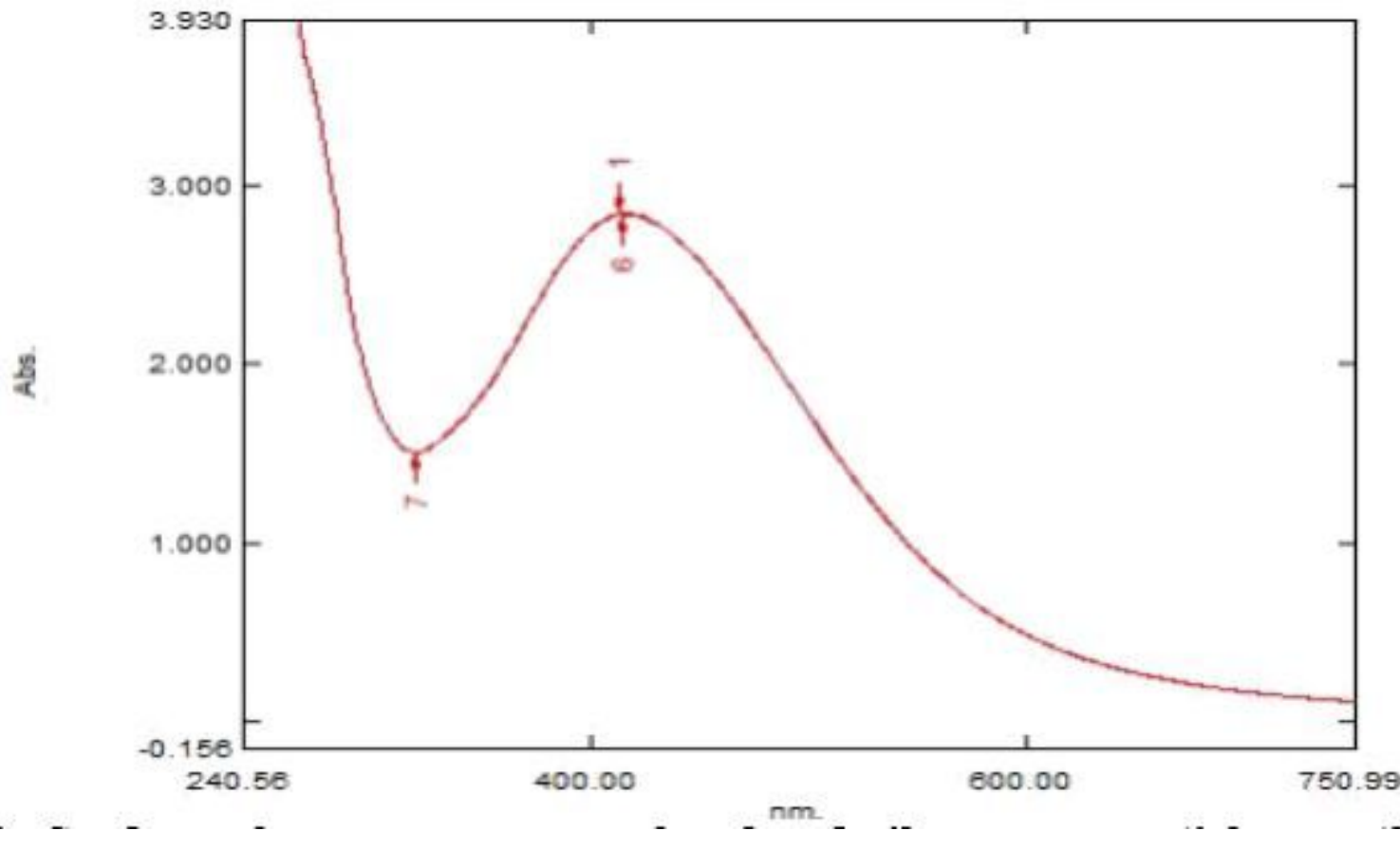

Figure 4

Surface plasmon resonance bands of silver nanoparticles synthesized from AgNO3 solution treated with culture filtrates of $3 \mathrm{DAl}$ 